\title{
Cuando caen los chicos y no los grandes: la corrupción a nivel subnacional en los casos de Callao y Tumbes
}

\section{Catching the big fish: subnational corruption in the cases of Callao and Tumbes}

\section{Cristhian Jaramillo $(*)$}

Grupo de Investigación de Partidos Políticos y Elecciones (GIPE)

ORCID: 0000-0002-4673-0565

Fecha de recepción: 21 de mayo

Fecha de aceptación: 6 de agosto

\section{ISSN en línea: 2415-2498}

Jaramillo, Cristhian (2019) «Cuando caen los chicos y no los grandes: la corrupción a nivel subnacional en los casos de Callao y Tumbes». Politai: Revista de Ciencia Política, Año 10, primer semestre, № 18: pp. $9-39$

DOI: https://doi.org/10.18800/politai.201901.001

*Licenciado en Ciencia Política y Gobierno por la Pontificia Universidad Católica del Perú. Investigador en la Oficina Nacional de Procesos Electorales (ONPE) y miembro del Grupo de Investigación de Partidos Políticos y Elecciones (GIPE). Tópicos de interés: estudios comparados sobre democracias, procesos electorales, partidos políticos y reforma política. 


\section{Resumen}

Entre el 2014 y 2015, 19 de 25 autoridades regionales peruanas se encontraban siendo investigadas por actividades vinculadas a la corrupción. A finales del 2018, 10 de los 19 involucrados eran juzgados con penas privativas de libertad y reparación civil a consecuencia de su accionar ilegal. Pero, a pesar de esta aparente eficacia a nivel judicial, ciertos casos con un número significativo de denuncias y antecedentes similares a los condenados se libraron de las sentencias en su contra.

De esta forma, la pregunta que atiende el presente paper es: ¿qué variables explican la evasión de sentencias efectivas en procesos vinculados a la corrupción por parte de los gobiernos subnacionales? La investigación se centra en la figura del gobernador regional (antes presidente regional), los delitos por los que se le acusa y el resultado judicial de los mismos entre el 2015-2018. Para ello, se realizó un estudio comparado de los casos Tumbes y Callao los cuales comparten similitudes interesantes como los delitos imputados, carencia de un presupuesto significativo y la ausencia de la nacionalización mediática de sus delitos durante el 2014 y años posteriores.

Los resultados de la investigación evidencian la presencia de dos variables: (in)eficiencia estatal y la sofisticación de las redes criminales. La conjugación de ambas es la que distingue la diferencia judicial en ambos casos destacando como estos pueden ser generalizados y analizados para la creación de políticas a favor de la lucha contra la corrupción.

Palabras clave: corrupción, política subnacional, fiscalización, impunidad. 


\begin{abstract}
Between 2014 and 2015, 19 of 25 Peruvian regional authorities were being investigated for activities related to corruption. At the end of 2018, 10 of the 19 involved were tried with custodial sentences as a result of their illegal actions. But, despite this apparent effectiveness at the judicial level, certain cases with a significant number of reports and a similar background to those convicted escaped the sentences against them.
\end{abstract}

Thus, the question addressed in this paper is: what variables explain the evasion of effective sentences in processes linked to corruption by subnational governments? The investigation focuses on the figure of the regional governor (formerly regional president), the crimes for which is accused and the judicial outcome between 2015 and 2018. For this, a comparative study of Tumbes and Callao cases was made, which share interesting similarities such as the imputed crimes, lack of a significant budget and the absence of media nationalization during 2014 and later years.

The results of the investigation show the presence of two variables: state efficiency and the sophistication of criminal network. The combination of both is what distinguishes judicial differences in both cases, highlighting how can be generalized and analyzed for the creation of policies in favor of the fight against corruption.

Keywords: corruption, subnational politics, accountability, impunity. 


\section{Introducción}

En el 2014, el entonces gobernador regional de Ancash, César Álvarez, capturaba toda la atención mediática y política del Perú siendo acusado de numerosos delitos como peculado, colusión, corrupción y el asesinato de su rival político Ezequiel Nolasco. Las investigaciones posteriores sobre este caso descubrirían toda una red de crimen, extorsión y manipulación mediática liderada por el ex gobernador ancashino para mantenerse en el poder y amedrentar a su oposición. Álvarez y Ancash despertaron un interés inusual por el desarrollo de la política subnacional y, entre el 2014 y 2018, 19 de 25 gobernadores regionales serían investigados por la Fiscalía por casos como: lavado de activos, colusión agravada, malversación de fondos para obras y proyectos, entre otros delitos. A finales del 2018, 10 de los 19 involucrados eran sentenciados a cumplir penas privativas de libertad y reparación civil.

Sin embargo, en algunos casos, y a pesar de una considerable cantidad de evidencia y denuncias en materia de corrupción, las acusaciones en contra de ciertos gobernadores no prosperaron durante un largo tiempo. La presente investigación busca explicar la diferencia entre los casos que han sido efectivamente sentenciados con los que gozaron de una aparente impunidad. Para ello, se realiza una comparación entre dos casos: Callao y Tumbes.

Las conclusiones de este estudio demuestran la presencia de dos variables: (in)capacidad estatal en los organismos fiscalizadores y la sofisticación de las redes criminales. La combinación entre ambas termina por explicar cómo en algunos casos las sentencias judiciales se evaden mientras que, en otros, los acusados son juzgados con rapidez. La metodología empleada es principalmente cualitativa con el uso de entrevistas semiestructuradas a actores claves y el seguimiento de los delitos cometidos en ambas unidades subnacionales mediante fuentes secundarias.

El presente paper se divide en cinco partes. En la primera se realiza un breve marco teórico sobre la corrupción y la capacidad estatal. Luego, se presentan los casos a analizar, sus similitudes y diferencias. En el tercer y cuarto apartado se analizan las variables ya planteadas: incapacidad estatal y sofisticación en delitos de corrupción. Y, finalmente, se presentan las conclusiones del estudio. Esta investigación también tiene 
como intención aportar una nueva perspectiva a los análisis sobre el tema de corrupción a nivel subnacional y proponer estrategias que combatan este tipo de actividades ilícitas.

\section{La capacidad estatal y la corrupción como objeto de estudio}

Es posible definir a la capacidad estatal desde distintas perspectivas. Algunos autores señalan a este factor como variable clave para la consolidación democrática, (Linz y Stepan 1996), "the rule of law” (O’Donnell 1993), la provisión de servicios hacia los ciudadanos (Rotberg 2004) y el crecimiento económico (Coatsworth 1998). Asimismo, la capacidad o fortaleza estatal se encuentra en función de la burocracia, las relaciones entre el Estado con actores sociales y su alcance espacial y social (Soifer y Vom Hau 2008). En la misma línea, Mann define al poder infraestructural como la capacidad del estado central a penetrar su territorio e implementar sus decisiones logísticamente (Mann 1986: 113).

De esta manera se reconoce tres variables presentes en el concepto de capacidad estatal. El primero es la facultad que posee el gobierno en cuestión para penetrar el territorio que gobierna. El segundo se basa en la capacidad para implementar su política de forma autónoma a los grupos sociales. Por último, la capacidad estatal también se evidencia al examinar el nivel de profesionalización o institucionalización del Estado para implementar políticas, extraer recursos y proveer de bienes públicos (Soifer y Vom Hau 2008, Giraudy 2012). El cumplimiento de una o más de estas tres variables supondrá una mayor fortaleza estatal.

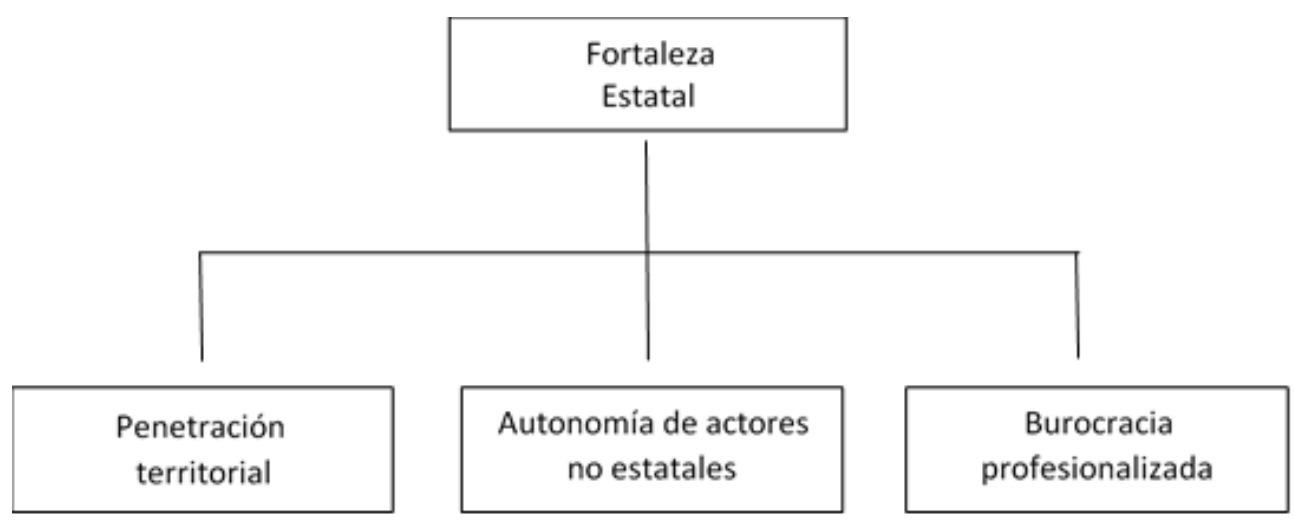


Por su parte, la corrupción puede ser definida como el abuso de una función pública o privada para obtener beneficios privados $y$ excluyentes, sin que estos sean necesariamente monetarios. Bajo una perspectiva jurídica, la corrupción es entendida como un vacío de la ley, una falla en el sistema de derecho en donde individuos actúan fuera de la legalidad. Los estudios jurídicos que se apoyan en esta línea plantean la subsanación de leyes como medida de solución para este fenómeno. Puesto que, una nueva y mejorada legislación supondría la reducción de los intereses de los individuos y su control con mecanismos punitivos (Mujica 2005).

Por otra parte, autores como Cartier-Bresson y Talahide (en Mujica 2005) definen a la corrupción como un fenómeno que involucra el interés económico e individual por lo que su solución radica en leyes más drásticas, incentivos mayores para no delinquir y, sobre todo, el fortalecimiento de la burocracia. Los estudios que siguen esta línea de investigación, mayormente de perspectiva económica, tienen como ámbito de análisis los altos espacios políticos y económicos en donde existe una lógica de clientelas y un patrón que determina las posibilidades y servicios frente a un cliente en medio de un contexto estable.

Sin embargo, ambos enfoques ignoran el trasfondo en el que se encierran las actividades corruptas. En principio, la corrupción en gran escala funciona si es que existe un complejo sistema de redes que involucran al comportamiento de los individuos y como estos se manejan dentro y fuera de la legalidad. La corrupción adquiere muchas formas siendo más un fenómeno social (Mujica 2005: 8-9).

Las actividades corruptas requieren de la participación de individuos y agentes que establezcan relaciones duraderas $\mathrm{y}$, como resultado, configuren una red social con características distintivas (Degenne y Forsé 1999; Wasserman y Faust 1994). De esta manera, para que se propicien actos de corrupción será necesaria la coordinación entre intereses y acciones de las distintas partes. Las actividades de corrupción necesitan de cierto grado de cooperación entre los actores y grupos para que su ejecución sea exitosa (Lindesmith 1941).

Estas actividades no son rutinarias; la corrupción, sobre todo a nivel de funcionarios estatales, requiere de ciertos espacios que son legitimados a través del tiempo. Las 
actividades corruptas, si desean preservarse con el tiempo, deben involucrar a individuos que puedan protegerlos de la fiscalización del Estado ganando de esta manera impunidad, influencia y preservando la continuidad de las acciones. Es este “grado de especialización” en los actores que infringen la ley lo que termina por explicar parcialmente el hecho de que los actos corruptos se mantengan en el tiempo y permanezcan sin ser juzgados. También, existe una relación directa entre el nivel de sofisticación del delito, la complejidad de las redes, los individuos que la componen y la capacidad que estos poseen para encubrir las acciones ilegales que se cometan. La manera en que estas redes se construyen, los actores que alcanzan y la influencia que ejercen determinarán el grado de impunidad del investigado.

Es posible distinguir las redes de corrupción por la presencia de dos características. La primera es la heterogeneidad de los bienes intercambiados en las transacciones corruptas. En esta línea, Mény (1999) sostiene que la corrupción moderna, como moneda, se ha desmaterializado sustituyéndose por favores o influencias. La red es la que autoriza estos tipos de transacciones demostrando la flexibilidad de esta organización.

La clandestinidad es la segunda característica básica de la corrupción. Para el nacimiento de una red de corrupción se requiere ciertos conocimientos fundamentales de las personas como: confianza entre los actores y la seguridad de poder predecir su accionar. La red se constituye como un espacio de relaciones interpersonales complejas que permiten crear confianza según un proceso de aprendizaje (Mujica 2005). La constitución de esta red tendrá como base la conveniencia y la pasividad de actores políticos que no pueden denunciar o fiscalizar porque están sujetos por múltiples relaciones clientelares.

En cambio, el por qué la corrupción se mantiene impune encuentra explicación en una multiplicidad de factores. Gibson (2005) plantea dos respuestas para el mantenimiento de este tipo de prácticas ilícitas dentro de los gobiernos subnacionales. El grado de nacionalización del problema es un factor que este contempla. Es decir, si la corrupción y/o violación de derechos se convierten en un tópico nacional esto produce que la estabilidad política de las autoridades locales se vea amenazada. Demasiada atención de los medios o de la sociedad civil tendrá como consecuencia el inicio de investigaciones 
o una respuesta por parte del gobierno nacional la que, en la mayor parte de casos, termina con demandas judiciales (Gibson 2005: 108).

Es también necesario considerar a la mediatización del acto de corrupción como variable explicativa a un mayor o menor grado de impunidad (Gibson 2005). El rol que los medios juegan al exhibir los delitos de corrupción es de vital importancia para los organismos fiscalizadores. La presión mediática tiene la capacidad de incluso movilizar a la ciudadanía o llamar la atención de los fiscalizadores para intervenir en el problema (Arévalo 2015).

\section{Los casos: Tumbes y Callao, entre la similitud y diferencia}

Una inicial mirada a la evidencia que se presenta a nivel subnacional destaca los casos de Ancash, Tumbes, Pasco y Callao como las cuatro regiones cuyos gobernadores presentan una gran cantidad de denuncias. De estos, el caso del Callao resulta ser excepcional ya que los delitos por los que se le acusa no produjeron durante varios años una condena legal. Recién en enero del 2019 se concretaría una sentencia en contra de Moreno luego de casi 20 años en la política subnacional. En cambio, la investigación que llevaría a prisión a Gerardo Viñas Dioses (Tumbes), se concluyó en menor tiempo luego de la fuga de este y su posterior captura en el Ecuador.

Cuadro 1. Número de casos en investigación y juicio de los Gobernadores regionales (2014-2018)

\begin{tabular}{|c|c|c|c|c|c|}
\hline \multirow[b]{2}{*}{ Departamento } & \multirow[b]{2}{*}{ Gobernador } & \multicolumn{2}{|c|}{ Número de casos } & \multirow[b]{2}{*}{ Total } & \multirow[b]{2}{*}{ Estado } \\
\hline & & $\begin{array}{c}\text { En } \\
\text { investigación }\end{array}$ & $\begin{array}{c}\text { En } \\
\text { juicio }\end{array}$ & & \\
\hline Ancash & César Álvarez Aguilar & 22 & 4 & 26 & $\begin{array}{l}\text { Pena } \\
\text { privativa }\end{array}$ \\
\hline Tumbes & Gerardo Viñas Dioses & 20 & 5 & 25 & $\begin{array}{l}\text { Pena } \\
\text { privativa }\end{array}$ \\
\hline Pasco & $\begin{array}{l}\text { Klever Meléndez } \\
\text { Gamarra }\end{array}$ & 20 & 0 & 20 & $\begin{array}{l}\text { Pena } \\
\text { privativa }\end{array}$ \\
\hline Callao & $\begin{array}{l}\text { Félix Moreno } \\
\text { Caballero }\end{array}$ & 10 & 2 & 12 & $\begin{array}{l}\text { Pena } \\
\text { privativa* }\end{array}$ \\
\hline Cusco & René Concha Lezama & 7 & 3 & 10 & $\begin{array}{l}\text { En } \\
\text { investigación }\end{array}$ \\
\hline Junín & Vladimir Cerrón Rojas & 7 & 3 & 10 & $\begin{array}{l}\text { En } \\
\text { investigación }\end{array}$ \\
\hline
\end{tabular}




\begin{tabular}{|c|c|c|c|c|c|}
\hline Cajamarca & Gregorio Santos & 5 & 4 & 9 & $\begin{array}{l}\text { Pena } \\
\text { privativa }\end{array}$ \\
\hline Madre de Dios & Jorge Aldazabal Soto & 8 & 0 & 8 & $\begin{array}{l}\text { Pena } \\
\text { privativa }\end{array}$ \\
\hline Ucayali & Jorge Velásquez & 4 & 3 & 7 & $\begin{array}{l}\text { En } \\
\text { investigación }\end{array}$ \\
\hline Huánuco & Luis Picón Quedo & 6 & 1 & 7 & $\begin{array}{l}\text { En } \\
\text { investigación }\end{array}$ \\
\hline Arequipa & Juan Guillén Benavides & 5 & 2 & 7 & $\begin{array}{l}\text { Pena } \\
\text { privativa }\end{array}$ \\
\hline Ayacucho & $\begin{array}{l}\text { Wilfredo Oscorima } \\
\text { Núñez }\end{array}$ & 3 & 2 & 5 & $\begin{array}{l}\text { Pena } \\
\text { privativa }\end{array}$ \\
\hline Lambayeque & $\begin{array}{l}\text { Humberto Acuña } \\
\text { Peralta }\end{array}$ & 4 & 0 & 4 & $\begin{array}{l}\text { En } \\
\text { investigación }\end{array}$ \\
\hline Puno & Mauricio Rodríguez & 4 & 0 & 4 & $\begin{array}{l}\text { En } \\
\text { investigación }\end{array}$ \\
\hline Apurímac & Elías Segovia Ruiz & 2 & 1 & 3 & $\begin{array}{l}\text { Pena } \\
\text { privativa }\end{array}$ \\
\hline Ica & $\begin{array}{l}\text { Alonso Navarro } \\
\text { Cabanillas }\end{array}$ & 2 & 0 & 2 & $\begin{array}{l}\text { En } \\
\text { investigación }\end{array}$ \\
\hline Lima & $\begin{array}{l}\text { Javier Alvarado } \\
\text { Gonzáles }\end{array}$ & 2 & 0 & 2 & $\begin{array}{l}\text { En } \\
\text { investigación }\end{array}$ \\
\hline Loreto & Yván Vásquez Valera & 1 & 1 & 2 & $\begin{array}{l}\text { Pena } \\
\text { privativa }\end{array}$ \\
\hline Moquegua & $\begin{array}{l}\text { Martín Vizcarra } \\
\text { Cornejo }\end{array}$ & 2 & 0 & 2 & $\begin{array}{l}\text { Caso } \\
\text { archivado }\end{array}$ \\
\hline
\end{tabular}

Fuente: La República (2017a) y Fiscalía de la Nación. Elaboración propia.

*En el caso de Félix Moreno se impuso una sentencia privativa que aún no es ejecutada debido a la fuga de este.

Por otra parte, es posible afirmar que los gobiernos regionales que poseen denuncias de corrupción comparten ciertas características en común. La primera es el tipo de organización política sobre la cual se apoyan. En los casos con mayor cantidad de denuncias, el gobernador regional pertenece a una organización regional o movimiento independiente. La inexistencia de partidos políticos nacionales que fiscalicen a los líderes regionales parece ser una variable explicativa a los altos índices de corrupción en las regiones. 
Las regiones que comparten una mayor similitud entre sí, pero con distintos resultados son Tumbes y el Callao. El primero, bajo la dirección de Gerardo Viñas Dioses, poseía 25 denuncias en su contra (20 en la Fiscalía de la Nación y 5 en el Poder Judicial) con delitos como la negociación incompatible, corrupción y colusión agravada lo que supuso su captura efectiva el 13 de junio del 2016. Mientras que el Callao, a mando de Félix Moreno Caballero, cuenta con 12 procesos (10 en la Fiscalía de la Nación y 2 en el Poder Judicial) y los delitos que se le impugna son los mismos que el primer caso: corrupción, colusión agravada y negociación incompatible. Sin embargo, a pesar de la cantidad de denuncias y el parecido que las mismas tienen, las investigaciones en el Callao se prolongaron por mucho más tiempo que su par de Tumbes. De la misma forma, ninguno de los dos casos gozó de importancia mediática o nacionalización de este problema.

Finalmente, ambos casos retan las preconcepciones sobre el funcionamiento estatal peruano. A pesar de que la lógica supone que las regiones más cercanas a la capital son juzgadas de manera más eficiente puesto que el centro posee comparativamente mejores recursos e instituciones que la periferia, en la práctica, sucede lo contario. Es en Tumbes en donde la fiscalización ha llegado a una sentencia judicial rápida y en el Callao parece existir un cierto grado de impunidad.

\section{La (in) capacidad estatal de los órganos de control: la Fiscalía de la Nación y Procuraduría Anticorrupción}

La justicia en el Perú en materia de corrupción es tarea de diversas entidades estatales. Entre estas se encuentran la Fiscalía de la Nación, la Procuraduría, la Contraloría de la República y el Poder Judicial. De estas, solo la Fiscalía de la Nación y la Procuraduría son las encargadas en investigar y denunciar de manera activa el posible accionar ilícito.

En consecuencia, es necesario realizar un análisis detallado de la capacidad que poseen estas dos instituciones: la Fiscalía de la Nación, con las Fiscalías Especializadas en Delitos de Corrupción de Funcionarios como oficinas específicas; y la Procuraduría Anticorrupción. Este análisis permitirá conocer hasta qué punto estas entidades son responsables de permitir un mayor o menor grado de impunidad. 


\section{La Fiscalía de la Nación: el funcionamiento legal}

El Ministerio Público es un organismo autónomo del Estado que posee funciones vinculadas a la defensa de la legalidad, los derechos ciudadanos y los intereses públicos. Esta entidad es el titular de la acción penal pública la cual ejerce de oficio. Entre los órganos que componen el Ministerio Público se encuentran: el Fiscal de la Nación, los Fiscales Supremos, los Fiscales Superiores, los Fiscales Provinciales, los Fiscales Adjuntos y las Juntas de Fiscales (Ministerio de Justicia y Derechos Humanos s/f).

Asimismo, es de competencia del Fiscal de la Nación poder designar a fiscales que intervengan en la investigación y hechos delictivos vinculados entre sí con intervención especializada. La legislación sobre este aspecto precisa que se debe fijar la competencia territorial, organización, funcionamiento y los mecanismos de coordinación y supervisión que correspondan a órganos especializados. Entre estas oficinas con tareas específicas se encuentra la Fiscalía Especializada en Delitos de Corrupción de Funcionarios.

Las Fiscalías Especializadas en Delitos de Corrupción de Funcionarios son las que conocen e investigan delitos que se encuentran tipificados en las secciones II, III, y IV, artículos 382 a 401 del Capítulo II, del Título XVIII del Código Penal. De esta forma, estas fiscalías son competentes para investigar delitos vinculados a organizaciones criminales según su gravedad, complejidad, repercusión nacional y/o internacional.

Para describir la situación en la que se encuentran las Fiscalías Especializadas en Delitos de Corrupción de Funcionarios es necesario recordar la definición de capacidad estatal propuesta por Giraudy (2012). Así, la capacidad de una oficina del Estado se define por la eficiencia que posee al tener una burocracia especializada, penetrar su territorio y poseer cierta autonomía. Con el fin de analizar estos factores dentro de la Fiscalía se realizaron entrevistas semi-estructuradas a los fiscales superiores de Lima, Callao y Tumbes examinando aspectos como su situación administrativa, la efectividad de su trabajo y la manera en que estos realizan las investigaciones en materia de corrupción.

Los resultados de estas entrevistas describen, en su mayoría, a una oficina estatal que carece de recursos suficientes para poder cumplir sus funciones. Este tipo de debilidades se acentúan en sus dependencias descentralizadas las que acusan de los mismos 
problemas, pero añadiendo la percepción que poseen sus funcionarios de abandono por parte del Estado.

\section{Un problema de estructura y recursos}

La evidencia recolectada mediante las declaraciones de los Fiscales Superiores Especializados en Delitos de Corrupción de Funcionarios prueba la existencia de diversos problemas dentro de esta institución que abarcan desde la organización de la entidad hasta los recursos económicos que esta dispone. En cuanto a la organización, las Fiscalías especializadas cuentan con un personal reducido. En su mayoría se componen por un fiscal superior, dos adjuntos y fiscales provisionales cuyo número varía según la dependencia en la que se encuentran.

Bajo este punto, los entrevistados coinciden que un equipo de tres personas difícilmente puede llevar a cabo una tarea tan compleja como es la investigación de todos los delitos vinculados a la corrupción de funcionarios. En palabras de la fiscal Yanet Vizcarra: “La fiscalía se hace cargo desde que alguien se roba un lápiz hasta una investigación grande. (...) Los casos por atender son demasiados lo que termina por afectar en todos los sentidos todas las investigaciones”.

De esta manera, un solo fiscal que, en un escenario ideal, debe manejar no más de 40 casos termina con hacerse responsable de aproximadamente 120. En total, los 5 mil 552 fiscales tienen una carga procesal que asciende a un millón 55 mil casos (La República 2016). Este exceso de trabajo tiene diversas consecuencias en el desempeño de los funcionarios pues las investigaciones no pueden realizarse en el periodo ideal de tiempo. A esto se le suma el hecho de que menos funcionarios se encuentran interesados en tomar este tipo de labor no solo debido a la alta carga que afrontan sino también a los altos riesgos que esta involucra.

Es necesario también entender que cada caso con el que trabaja la Fiscalía requiere de distintas maneras de investigar el delito en cuestión y demanda un diferente tipo de inversión por parte del Estado. En palabras de la fiscal del Callao: 
Se nos hace imposible. (...) Muchas veces las investigaciones se descuidan por eso mismo, son demasiadas y la capacidad humana no puede con todas. Acá, por ejemplo, solo nos centramos en las que sabemos que nos van a dar evidencia, pero esta estrategia también trae desventajas. Lo ideal sería atender todas, tener más personal, más gente capaz, pero con lo de los fiscales provisionales esto parece que no va a ser así. (...)

La carga fiscal que enfrentan estos funcionarios se ve de alguna manera aliviada gracias al trabajo de los fiscales provisionales. Estos son parte de la institución, pero no se encuentran de manera constante dentro de la Fiscalía. No obstante, el trabajo de los fiscales provisionales, como la fiscal del Callao apuntó, generan muchas veces problemas en la continuidad del caso investigado.

Así, los casos que requieren un mayor tiempo se ven afectados debido a la constante rotación del personal. Sin una estabilidad laboral dentro de esta institución, la calidad de la labor disminuye. Yanet Vizcarra precisa el hecho de que los fiscales provisionales pueden “cambiar de sede o de puesto en el momento que lo soliciten” por lo que un nuevo funcionario que entra a cubrir la nueva vacante no cuenta "ni con información ni con la capacitación suficiente para asumir el reto". No existe, en las Fiscalías Descentralizadas, la práctica de dejar información o capacitar al siguiente funcionario en los casos a investigar. En consecuencia, el progreso logrado en los meses o años de investigación en un determinado caso termina interrumpiéndose debido al movimiento de los fiscales provisionales.

A pesar de estos problemas con la organización de la Fiscalía, este parece no ser el principal de los inconvenientes. Curiosamente, al cuestionar a los fiscales sobre las dificultades que encuentran dentro de su trabajo todos señalaron a la falta de recursos como el factor más determinante. El problema económico en la Fiscalía de la Nación ha sido un tema recurrente en los últimos cuatro años. En el 2015, el entonces Fiscal de la Nación Pablo Sánchez declaraba en el Pleno del Congreso la necesidad de tener un mayor presupuesto para el Ministerio Público. Esto se debía a que, según las cifras de ese año, habían sido asignados solo 1,500 millones de soles de los 3,900 millones inicialmente solicitados por su institución (RPP Noticias 2015). Sánchez sostenía que la carencia en recursos no permitía atender la enorme carga fiscal que posee esta institución impidiendo contratar a más fiscales. En noviembre del mismo año, la 
Fiscalía de la Nación exigiría al Ministerio de Economía y Finanzas la asignación de recursos adicionales para solventar sus gastos. El monto era de 18 millones de soles el cual serviría para pagar los sueldos de más 789 nuevos fiscales (Correo 2015a).

Como es de suponer, el presupuesto que se le adjudica a las Fiscalías no termina por cubrir todas sus necesidades y, en especial, perjudica al número de capacitaciones realizadas y al número de peritos que los fiscales pueden solicitar. Con los recursos limitados que cuentan las Fiscalías Descentralizadas, los peritos que se contratan no abarcan todos los casos y presentan dificultades como el tiempo limitado de la investigación. Al respecto, Francisco Arata sostiene:

“El tema de los peritos es fundamental. Muchas pericias cuestan demasiado y el Estado gasta. Nuestros peritos no están en condición de atender pericias difíciles, por ejemplo. Y, el Ministerio Público tiene que contratar a profesionales de afuera que cobran muchísimo.”

Así, sin profesionales a cargo de los casos a tiempo completo, con una excesiva carga fiscal, sin capacitaciones suficientes, sin peritos especializados y sin traspaso de conocimientos, la Fiscalía queda sumamente debilitada al momento de defender su investigación frente a un juez. El fiscal Alexander Pérez coincide con Yanet Vizcarra en la dificultad de una defensa en un juicio oral frente a investigados que cuentan con mayores recursos que la Fiscalía. A esto, Yanet Vizcarra precisa:

"Y vamos, estos señores investigados no son pobrecitos, tienen recursos, tienen buenos estudios de abogados. Y no voy a decir que en la fiscalía somos unos incompetentes, pero no es lo mismo pelear un fiscal contra cinco abogados (...). Sí, vamos a discutir y vamos a pelear porque es nuestro deber. (...) Pero para afuera se opina que no se trabaja. Nosotros tenemos falencias lógico, pero también queremos hacer bien las cosas en la medida en que tengamos todos los elementos.”

Por último, los fiscales especializados reconocen el grado de vulnerabilidad en el que se encuentran. Puesto que, a pesar de investigar casos tan complejos como la corrupción de funcionarios o delitos de crimen organizado, los fiscales no cuentan con ningún tipo de medida preventiva contra posibles represalias de organizaciones criminales. Como la fiscal Nelly Castro destaca: “(...) estamos desprotegidos, cualquier día nos pasa algo y 
no tenemos los medios con qué defendernos. Lo que investigamos es peligroso y pesado y por eso no muchos desean estos puestos”.

De esta forma, los problemas que posee la Fiscalía como institución afecta de sobre manera a las investigaciones realizadas. Tanto en presupuesto como en la estabilidad del personal y la seguridad, los fiscales son conscientes de las limitaciones de su cargo. Muchas de estas deficiencias son compartidas por la Procuraduría Pública, aunque con ciertos detalles que los diferencia.

\section{La Procuraduría Pública Especializada en Delitos de Corrupción: mayor capacidad, menor cooperación}

El Ministerio de Justicia y Derechos Humanos, al iniciarse la gestión del expresidente Ollanta Humala, recibió como encargo la reestructuración de las procuradurías públicas que se encargaban de la defensa estatal en temas de corrupción. Para ello, esta institución fusionó la Procuraduría Pública Ad Hoc para los casos Fujimori-Montesinos y la Procuraduría Pública Especializada en Delitos de Corrupción. Asimismo, se creó una Unidad de Análisis Financiero y Cooperación Internacional y una Unidad de Análisis de Información (Observatorio Anticorrupción) para incorporar unidades de inteligencia. Y, por último, se enfocó una estrategia de recomposición del sistema descentralizado con el fin de mejorar la situación en las regiones (Ministerio de Justicia y Derechos Humanos s/f).

De esta manera, la organización se modificó para impulsar una mejor descentralización añadiendo al Procurador de cada región las tareas de supervisión y control. Gracias a esta reforma, la Procuraduría tuvo presencia en todo el país con 15 Procuradurías, 12 Coordinaciones y 9 Oficinas (Ministerio de Justicia y Derechos Humanos s/f).

Como es evidente, la Procuraduría Pública ha gozado de ciertas concesiones por parte del Estado central estructurándose de mejor forma que las Fiscalías Especializadas en Delitos de Corrupción de Funcionarios. Se ha llevado un proceso de reforma dentro de esta oficina lo que supone una ventaja por sobre sus pares en las Fiscalías Especializadas. Las declaraciones recopiladas y la investigación realizada sobre el estado de esta entidad estatal evidencian ciertos parecidos entre ambas oficinas, pero también destacan problemas únicos presentes en las Procuradurías. 


\section{La cooperación institucional: la Procuraduría frente a la Fiscalía.}

Tanto la Fiscalía como la Procuraduría son entidades que bajo un simple análisis guardan una cantidad considerable de similitudes en cuanto a deficiencias institucionales. El caso económico es el primer factor que ambas instituciones comparten. Los Procuradores entrevistados de las regiones de Tumbes y Callao coinciden que los salarios no son los óptimos y que la poca cantidad de recursos que poseen reducen significativamente su capacidad de apoyo en las investigaciones. Adriano Aguilar, Procurador de Tumbes, señala:

Quisiéramos hacer más, pero no se puede con lo que se gana. Cada uno ya hace horas extra por su voluntad y compromiso. Con salarios más altos mejores profesionales podrían venir y la institución mejoraría. Pero es una realidad que no tenemos. (...) Mejores sistemas e infraestructura también sería lo ideal, pero por el momento se trabaja con lo que se tiene.

Paradójicamente, esta debilidad económica no se traduce en altos niveles de movilidad en profesionales como sí sucede en la Fiscalía de la Nación. En el caso de los procuradores, los puestos son más estables y los funcionarios se encuentran mejor capacitados debido a que permanecen a cargo de sus oficinas un considerable periodo.

Asimismo, al igual que en la Fiscalía, la creciente carga laboral representa otra dificultad significativa dentro de sus funciones. Al igual que las Fiscalías, la Procuraduría cuenta con un personal reducido para un trabajo apabullante a llevar a cabo. En el caso del Callao, solo tres personas tienen una carga de 700 a 800 casos al año. Y, aunque el número de casos parece reducirse a nivel provincial, según las declaraciones del Procurador de Tumbes las cifras varían entre 400 a 500 casos por persona.

Esta carga fiscal ha supuesto en la Procuraduría, a diferencia de sus pares, la elaboración de un sistema que priorice ciertos casos sobre otros. De esta forma, los procuradores manejan una base de datos en las que identifican los casos más apremiantes y los ordenan de la siguiente manera:

1. Por repercusión nacional: casos vinculados a individuos o instituciones que afectan a toda la nación. Esta categoría también incluye casos con alta presión mediática. 
2. Por cantidad de imputados: casos que presentan una gran cantidad de personas denunciadas, lo que serviría como indicio de una organización criminal, o cuyos individuos ocupan cargos importantes dentro del Estado.

3. Diligencias: ordenadas por la Fiscalía u otro organismo a investigar.

4. Monto/prejuicio: casos según la cantidad de pérdida monetaria en detrimento del Estado.

Bajo este punto, es posible afirmar que las deficiencias entre la Fiscalía y la Procuraduría son similares. No obstante, es la segunda oficina la que cuenta con un mayor grado de profesionales capacitados y sin una alta movilidad de sus funcionarios. $\mathrm{Y}$, son estos burócratas capacitados los que curiosamente menos dispuestos se encuentran en coordinar y colaborar con la Fiscalía de la Nación.

Esta poca iniciativa para colaborar se debe a que los Procuradores tienen una percepción negativa de los Fiscales Especializados a los cuales se les acusa de desperdiciar la documentación que poseen y de ser los principales causantes del archivamiento de los casos. Los Procuradores son conscientes que los fiscales no cuentan ni con la logística necesaria ni con los peritos ideales para llevar a cabo sus investigaciones y, sin embargo, aún consideran a las deficiencias en la capacidad de sus funcionarios como la principal explicación para la impunidad.

El Procurador del Callao, Engie Herrera, manifestó en su momento que la figura de los fiscales provisionales es la que permite que la impunidad siga vigente. Puesto que, son estos funcionarios los menos competentes para ejercer una función tan importante como es la investigación de delitos vinculados a la corrupción. En el caso del Callao, argumenta Herrera, las denuncias de corrupción parecen indicar la existencia de una red sistemática que oculta muy bien su evidencia y que toma ventaja de las deficiencias en las instituciones y el apoyo nulo del Estado para poder continuar delinquiendo.

Un comparativo entre la Procuraduría y la Fiscalía demuestra que la primera posee niveles mucho más altos en cuanto a fortaleza entre ambas instituciones. Su capacidad burocrática es superior y posee un alcance territorial considerable debido a su estructura específicamente diseñada para este propósito. Sin embargo, la diferencia de capacidades entre las oficinas a cargo de Procuradores y Fiscales hace que los primeros sean más críticos en cuanto a la labor de los segundos. 
El análisis de ambas instituciones permite realizar ciertas conclusiones sobre el estado de las mismas. En ambos casos, estas entidades no cuentan con el personal adecuado (en número o en capacidad) y perciben un grado de abandono por parte del Estado. Así, sin recursos, logística, con una carga fiscal abrumante y con poca coordinación, no es extraño que casos con investigaciones en delitos de corrupción tiendan a mantenerse impunes. Sin embargo, y como se ha señalado en anteriores apartados, existen casos en los que los acusados sí son condenados por sus delitos.

De esta forma, la debilidad institucional no termina por explicar de manera satisfactoria el por qué en algunas situaciones se produce una evasión de la fiscalización y en otros esta fracasa. El siguiente apartado analiza un factor más al que se denomina sofisticación de las redes de corrupción la cual se define como la capacidad que posee cada uno de los casos analizados en evadir la justicia y que resulta crucial para explicar las diferencias entre el Callao y Tumbes.

\section{La sofisticación de las redes de corrupción}

\section{Callao y Chimpum Callao: una manera de hacer política}

El gobierno regional del Callao, desde el año 2006 hasta el 2018, se mantuvo bajo la administración de un solo movimiento regional denominado Chimpum Callao. Esta organización política fue fundada el 2 de agosto del 2005 en el distrito de la Perla, Callao, por Alexander Kouri. El fin principal de esta agrupación era participar en las elecciones municipales y regionales del 2006 de las cuales salieron victoriosos con Kouri como Presidente Regional y Félix Moreno como Alcalde Provincial. La organización política también participó en las elecciones del 2010 y 2014 obteniendo victorias electorales en ambas instancias convirtiéndose en el movimiento a nivel subnacional con más éxito a nivel electoral.

Hasta finales del 2018, el Callao se encontraba bajo el mando de Félix Moreno quien inició su carrera política a través de las juventudes del Partido Popular Cristiano (PPC). Pero, todos sus éxitos electorales comenzaron como representante de Chimpum Callao. Así, en 1995 era elegido regidor de la Municipalidad Provincial del Callao. Entre 1998 al 2006, Félix Moreno ocupaba el cargo de alcalde de la Municipalidad Distrital de Carmen de La Legua-Reynoso por el mismo movimiento político. Terminado este proceso, Moreno tentó la Presidencia Regional del Callao ganando en las Elecciones 
Regionales y Municipales del 2010 y 2014. Estas dos últimas victorias electorales también las haría como líder de Chimpum Callao (INFOgob 2017).

Al igual que su gran experiencia en la política subnacional, Moreno también posee una larga suma de denuncias en contra de su persona y gestión. Hasta el 2017, los cargos imputados en su contra variaban desde corrupción, malversación de fondos, lavado de activos, hasta delincuencia organizada. Luego de años de investigación, Moreno sería procesado y condenado de forma efectiva en enero de 2019, cuando este ya no poseía un cargo político.

Las denuncias contra Moreno se iniciaron en agosto del 2014, cuando la Fiscalía Especializada en Delitos de Corrupción de Funcionarios del Callao presentaba una acusación contra su persona por la venta de un terreno, el fundo Oquendo, a un precio subvaluado. Al gobernador regional se le acusaba de los delitos de peculado, colusión agravada y negociación incompatible (Perú 21 2014).

Un año después, en setiembre del 2015, a la administración de Moreno se le imputaba el haber pagado con fondos públicos los servicios de capacitación docente. Dicha capacitación le costó al Estado el monto de seis millones de soles, pero esta actividad en sí nunca llegó a realizarse. La Contraloría General de la República sería la que identificaría la responsabilidad de funcionarios y ex funcionarios del Comité de Administración del Fondo Educativo del Callao (CAFED). También esta detectó que dos de estos seminarios fueron simulados usando documentos de eventos anteriores con la finalidad de sustentar el gasto (Perú 21 2015a).

El mismo año, la Fiscalía denunciaría a Félix Moreno ante el Poder Judicial por el delito de peculado. Esta violación de la ley se encontraría relacionada con la construcción de un spa para generales en las instalaciones del Cuartel General del Ejército con el dinero que había sido destinado a su región. En otro caso, la Fiscalía solicitaría once años de prisión efectiva para Moreno y dieciséis personas más por la construcción inconclusa de la sede CORPAC (Corporación Peruana de Aeropuertos y Aviación Comercial) y la defraudación de 21 millones nuevos soles (Perú 21 2015b). 
Otra acusación, aún más grave que las anteriores, fue la expuesta a finales del año 2015. El ex gobernador del Callao era señalado como autor intelectual del asesinato de Wilbur Castillo Sánchez. Roberto Castillo, hermano del fallecido, acusaba a Félix Moreno, Patricia Chirinos, la alcaldesa de La Perla, y al entonces congresista Rogelio Canches de ser los autores intelectuales. Castillo sostenía que todos estos guardaban relación con las actividades del narcotraficante “Caracol” (Perú 21 2015c).

A pesar de esta grave denuncia, las acusaciones contra Moreno no se detuvieron. En el 2016, el Ministerio Público detectó irregularidades en la obra "Mejoramiento de la Avenida Néstor Gambetta” la cual fue ejecutada por las constructoras brasileñas Andrade Gutiérrez y Queiroz Galvao. La Contraloría, revisando el caso, acusaría al gobierno del Callao por las pérdidas que el proyecto generó al Estado que ascendían a casi 55 millones de soles (Perú 21 2016).

En febrero del 2017, la Fiscalía Anticorrupción formalizó una investigación preparatoria contra Moreno por el caso de un terreno en Ventanilla. Al gobernador regional del Callao se le acusaba de haberse apropiado, supuestamente, de la venta de algunos predios del proyecto Especial Ciudad Pachacútec (Perú 21 2017a). En el 2019, las acusaciones contra Moreno tuvieron por primera vez un impacto real cuando a inicios de este año fue condenado a prisión preventiva debido a la investigación que se realizaba por una presunta coima de 2.4 millones de dólares a la constructora brasileña Odebrecht (Perú 21 2017b, Ojo Público 2017b).

\section{El caso de Moreno: la formación y la profesionalización de una red}

Un análisis de los delitos de los que se acusa a Moreno desprende dos grandes conclusiones. La primera es que todos estos involucran al ex gobernador con delitos como colusión agravada, corrupción y negociación incompatible. Asimismo, todas estas denuncias no terminaron por ascender a una mayor instancia ya que se optó por el sobre seguimiento de las mismas, con excepción del caso Oquendo y CORPAC que fueron por los que se dictaría una sentencia de prisión en contra de Moreno.

Bajo este punto, es posible preguntarse el por qué las investigaciones que inició la Fiscalía y Procuraduría no prosperaron durante un largo tiempo en condenas efectivas. 
Para obtener una respuesta satisfactoria es necesario ampliar la óptica de estudio y centrarse en los vínculos entre el Gobernador del Callao con otros actores. El mapeo de personas denunciadas ante la Fiscalía, los miembros del partido político Chimpum Callao y el círculo cercano de Félix Moreno demuestran la existencia de una compleja red. La construcción de esta misma se basó en los aportantes registrados por la ONPE y personas vinculadas directamente a Chimpum Callao. Todo ello gracias a la investigación realizada por Ojo Público en su proyecto Fondos de Papel (2017a).

En el siguiente gráfico se resumen las relaciones que establecen estos individuos y los delitos a los que están conectados.

Gráfico 2. Visualización de las relaciones de miembros del partido Chimpum Callao y denuncias

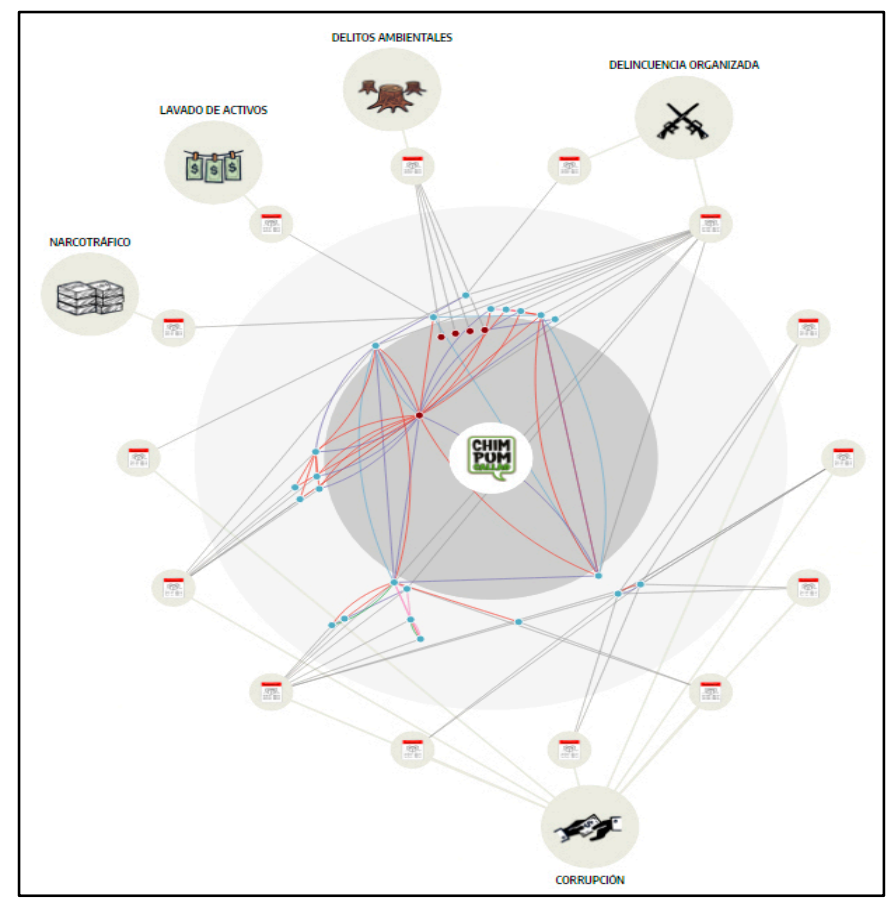

penales

Fuente: Ojo Público (2017a).

Entonces, es posible afirmar la existencia de relaciones entre las personas que financian al partido de Chimpum Callao y delitos vinculados al narcotráfico, corrupción, lavado de activos, delincuencia organizada y delitos ambientales. Son 25 individuos los que se encuentran involucrados en esta red siendo también partícipes en la esfera política a nivel nacional como local. Los vínculos entre todas estas personas varían desde un nivel amical, familiar hasta de complicidad, laboral, societaria y de beneficio. Se resalta la participación de: 
- Marcelo Odebrecht: ex CEO de Odebrecht, preso por soborno en Brasil y colaborador eficaz en el caso Lava Jato.

- Jorge Simoes Barata: ex directivo de Odebrecht en el Perú. Este detalló los sobornos de su empresa a autoridades peruanas.

- Luis Favre: publicista y vinculado a millonarias campañas electorales. Relacionado con Félix Moreno al haber trabajado en su campaña electoral en el 2014.

- Fernando Gordillo Tordoya: ex gerente de la región Callao, exgerente provincial de desarrollo urbano y procesado en el caso de Vía Expresa Fauccett.

- Roberto Martínez Vera Tudela: ex funcionario de la municipalidad del Callao y vinculado a una red de chuponeo en esta región.

Curiosamente, también se encuentran involucrados dentro de la organización personas cercanas a Moreno que tienen una influencia importante tanto en su vida personal como política. Entre estas destacan:

- Rosemary Segura Neyra: pareja de Félix Moreno e investigada por el delito de lavado de activos.

- Yesenia Delia Segura Neyra: familiar de Rosemary Segura Neyra. Representante de "Fugaz”, proyecto para revalorar el Callao histórico y exasesora de imagen en la Municipalidad de San Miguel.

Es necesario resaltar también que la red formada no depende únicamente de Moreno. Al contrario, esta se asienta gracias a los años de gobierno que ha mantenido Chimpum Callao sobre su circunscripción. De esta forma, este movimiento político cuenta con:

- Alexander Kouri: fundador del partido Chimpum Callao. Actualmente cubre condena por casos de corrupción e investigado por los casos de chuponeo y de Vía Expresa Faucett.

- Eduardo Javier Bless Cabrejas: alcalde y ex regidor de la Municipalidad de San Miguel.

- Omar Alfredo Marcos Arteaga: alcalde de Ventanilla.

- Juan Sotomayor García: presidente de Vamos Perú, alcalde provincial del Callao e implicado en la red de chuponeo del Callao. 
Así, es posible determinar la existencia de un grado de sofisticación en la red formada pues los actores que la conforman poseen un alto nivel de injerencia a nivel nacional como internacional. Es la red que forma Moreno y las conexiones multinivel que establece lo que evita, en cierta medida, que las denuncias realizadas por distintas instituciones posean sentencias firmes.

La impunidad en este caso parece mantenerse gracias a dos aristas. La primera es el gran poder económico y de recursos que tienen los individuos a quienes se les acusa. Esto permite evitar que las denuncias lleguen a mayores al enfrentarse en el juicio oral a los fiscales. En palabras de la fiscal Yanet Vizcarra:

Claro, acá tú te puedes preparar todo lo que quieras y todo, pero (...) ellos te traen a su buffet de abogados y tú solo. Así, en unos cuantos pasos hacen que tu denuncia se archive (...) no tenemos ni tiempo para revisar bien y ellos sí tienen todo. Es un tema de dinero claro, pero también de que la capacidad de ellos es superior a la nuestra.

Los recursos que estos poseen también sirven para evitar la fiscalización efectiva. Por otro lado, la manera en que estos se reúnen, acuerdan y utilizan artificios legales para justificar su accionar es prueba de una gran capacidad de organización la cual no se apoya en un solo individuo sino involucra a varias personas lo que dificulta en gran sentido las investigaciones.

La evidencia presentada señala la existencia de una gran capacidad para delinquir dentro del gobierno del Callao el cual también toma ventaja de la gran debilidad institucional de las Fiscalías y Procuraduría Anticorrupción. Esta capacidad, representada por el alto grado de sofisticación de la red, se ha visto cimentada gracias a los años de Chimpum Callao en el poder, la cantidad de individuos, tanto nacionales como internacionales que involucra la red, y los recursos que estos manejan.

\section{El caso de Tumbes y la aparente fortaleza estatal}

Gerardo Viñas Dioses llegó a ocupar el cargo de gobernador regional en Tumbes en las Elecciones Regionales del 2010. Aunque, su participación en la política de su región comenzó en el 2002 postulándose como consejero regional siendo parte de la 
organización política independiente “Manos limpias por un Tumbes mejor”. Tras la derrota electoral de esta organización, Viñas Dioses, siguiendo el patrón de los políticos a nivel subnacional, cambió de organización para postularse al cargo de Congresista en las elecciones generales del 2006. También en esta ocasión, bajo el apoyo de la organización política “Concertación Descentralista”, Viñas Dioses fracasó en su intento de ser elegido. Pero, esta derrota política no mellaría su intención de ocupar un puesto de poder y en el 2006, bajo el "Partido Nacionalista Peruano”, se postularía al puesto de alcalde provincial y su intento, al igual que el resto, terminaría con otra derrota electoral. En el 2010, por fin el movimiento regional "Luchemos por Tumbes" fue el que llevó al poder a Viñas Dioses (INFOgob 2017).

Sin embargo, el periodo de gobierno de Viñas Dioses se vería tempranamente interrumpido debido al abandono del cargo y la posterior fuga de este el 04 de junio del 2014. En esta fecha, el Poder Judicial aceptaba el pedido de prisión preventiva en su contra que contemplaba acusaciones vinculadas a delitos como corrupción, lavado de activos y compras y contrataciones irregulares durante su gestión (RPP Noticias 2016).

Una de las primeras denuncias en contra del ex gobernador regional de Tumbes fue las irregularidades encontradas en la obra "Mejoramiento y Ampliación del Sistema de Agua Potable de los distritos de Corrales, San Jacinto, Pampas de Hospital y San Juan de la Virgen”. Esta obra en cuestión suponía la pérdida de cerca 10 millones de soles para el Estado peruano.

Viñas Dioses también fue acusado de colusión con un perjuicio económico de más de 9 millones 200 mil soles al Estado por haber reconocido ilegalmente una liquidación irregular a favor de la empresa A\&J Inversiones SAC mediante una conciliación dentro de un proceso arbitral (El Comercio 2016). A esto se le suma la acusación realizada por el Ministerio Público sobre la venta irregular de 36 hectáreas en Punta Sal, denuncia por la cual el ex gobernador optó por fugarse del país.

Tras la huida de Viñas Dioses, los procedimientos para su búsqueda y captura comenzaron con la iniciativa del Ministerio del Interior que llegó a ofrecer una recompensa de 100 mil nuevos soles por su apresamiento o información que dé lugar a este. El 13 de junio del 2016, cerca de dos años después de su fuga del país, Viñas 
Dioses fue encontrado en Ecuador de donde fue expulsado para posteriormente ser entregado a las autoridades peruanas.

Tras su captura, los juicios a Viñas Dioses tomaron lugar y, en medio de estos, se descubrió mayor evidencia que lo vinculaba con otros delitos. El 4 de noviembre del 2016, el exgobernador regional de Tumbes sería condenado a 11 años de prisión por colusión y defraudación. El 7 de octubre del 2017, el Poder Judicial amplió por siete meses más la prisión preventiva para Gerardo Viñas Dioses. Para ese momento, el exgobernador regional de Tumbes ya había sido sentenciado con siete años de cárcel por casos de corrupción relacionado a la obra de mejoramiento antes descrita. De acuerdo a esta nueva acusación, y a la fiscal Miriam Umbo Ruiz, se solicitó esta ampliación para poder investigar otro caso de abandono de una obra que se valorizaba en cinco millones de soles (América Tv, 2017). En diciembre del mismo año, el Juzgado Unipersonal de Contralmirante Villar dictó otros tres años de prisión suspendida contra Viñas Dioses por el delito contra la administración pública en la modalidad de abuso de autoridad cuyo accionar condicionó la entrega ilegal de bienes del Estado (La República 2017b).

\section{La inexperiencia para delinquir como variable}

Es importante reconocer, bajo este punto, las diferencias significativas que posee el caso de Tumbes al compararse con el Callao. En primer lugar, y a pesar de la notoria experiencia política de Viñas Dioses, el caso de Tumbes no cuenta con una organización tan bien consolidada como lo es Chimpum Callao. Las participaciones de Viñas Dioses dentro de la política subnacional tuvieron como resultado en su mayoría la derrota electoral pasando de una organización regional a otra. En contraste, Chimpum Callao ya era una organización política sólida que no depende completamente de la imagen de Félix Moreno para poder conseguir resultados electorales positivos. La diferencia principal entre ambos casos es la compleja red que se construyó en el Callao frente a la inexistencia de una organización parecida en Tumbes.

También es evidente que, aunque los cargos imputados en ambos casos son similares (corrupción, malversación de fondos, venta irregular de terrenos), las dimensiones de los delitos son completamente diferentes. En el caso del Callao, muchos de los delitos 
investigados involucran a agentes internacionales, como la constructora brasileña Odebrecht, mientras que los delitos de Tumbes se focalizan solo en la figura del exgobernador de Tumbes.

La falta de una organización que soporte el accionar ilegal de Viñas Dioses fue uno de los factores que contribuyó a su intervención judicial y posterior sanción. El caso del Callao, como ya se ha reportado, parece sostenerse sobre un conjunto de individuos que comparten responsabilidades en los delitos por los que se le acusa. En Tumbes, en cambio, se hace evidente la torpeza política por parte de Viñas Dioses y la total responsabilidad del mismo. Como señala el Fiscal José Antonio Garay:

(...) yo creo que se solucionó el caso por la precipitación del acusado. (...) al momento de darse la denuncia contra él y presentarse las pruebas en el juicio oral, el juez decretó la posibilidad de una prisión preventiva. Luego se dio a la fuga (...) ningún inocente va a huir pues (..) no supo hacerla.

Es esta poca destreza política la que diferencia ambos casos. El "no saber hacerla” es el factor que termina por definir las diferencias entre ambos casos. Tanto en Tumbes como en el Callao, las entidades fiscalizadoras no se encuentran en óptimas condiciones de trabajo y se detectan debilidades tanto en el centro como en la periferia. La diferencia de resultados se encuentra en la variable denominada sofisticación de la red criminal. El Callao representa un caso en donde los delitos de corrupción no se han analizado a profundidad debido a diversos factores como la fuerza política y económica de los involucrados, la estabilidad política que estos gozan y una red de corrupción desarrollada. Contrario a ello, Tumbes presenta un caso en donde los delitos de corrupción se han llevado con mayor torpeza y menores recursos lo que produjo que una acusación fiscal propiciara la huida del acusado.

\section{Conclusiones}

La presente investigación explica la diferencia entre casos de corrupción efectivamente sentenciados con los que gozaron de una aparente impunidad de forma acotada. Para ello, se realizó un estudio comparado de las regiones Callao y Tumbes, ambos con un número significativo de denuncias e investigaciones judiciales, pero con resultados distintos. 
Tras el análisis realizado, es posible afirmar que la diferencia entre la rapidez judicial en Tumbes y la demora de esta en el Callao depende de dos factores: la debilidad institucional de las entidades fiscalizadoras y la sofisticación de la red delictiva. Sobre el primer aspecto es importante destacar la poca capacidad estatal que poseen las fiscalías y procuradurías. En contra de lo que dicta la teoría, tanto las entidades fiscalizadoras en el centro como las de la periferia poseen una serie de problemas que dificulta su labor. Entre estos se encuentran: la inestabilidad laboral, una excesiva carga fiscal, poca coordinación entre las instituciones fiscalizadoras, falta de presupuesto y la falta de capacitación del personal. Es esta debilidad la que impide que las denuncias sean efectivamente fiscalizadas.

Sin embargo, el factor de debilidad institucional no termina de explicar por completo la diferencia judicial en los casos estudiados. Para ello, esta investigación se apoya en el seguimiento del partido político Chimpum Callao y la manera en que este y su líder, Félix Moreno, se vincula con otros actores tanto de la escena nacional como internacional. Moreno, a diferencia de Viñas Dioses, cuenta con el apoyo de una organización política que se ha consolidado en el poder a través de los años y que tiene una gran ratio de victorias electorales. Es esta red de influencias y el accionar premeditado al cometer delitos lo que mantuvo a Moreno fuera de prisión durante un gran periodo. Sus delitos son más complejos de investigar ya que involucran a personas con una gran cantidad de recursos, poder e influencia. Esto, sumado a entidades fiscales deficientes, explica la demora en una sentencia firme.

Por otra parte, esta investigación también reconoce y considera que existen más factores que influyen en la investigación y resolución de casos tan complejos como la corrupción. El primero de ellos es la nacionalización del problema y posterior mediatización, variable mencionada en uno de los apartados de este estudio, la cual presiona a las entidades fiscalizadoras a investigar o, cuanto menos, exigir prisión preventiva para el acusado de corrupción. Un claro efecto de este tipo de factor y su influencia es el caso de Ancash en el 2014, cuya nacionalización ocurrió tras el asesinato de Ezequiel Nolasco lo cual produjo el descubrimiento de toda una red criminal. Asimismo, aunque no analizado en esta investigación, una variable igual de importante es la influencia de los partidos políticos y la sociedad civil en la lucha contra la corrupción. Sin embargo, por razones de tiempo y recursos el paper se ha centrado 
solo en la debilidad institucional y la sofisticación de las redes delictivas, evidenciando la forma en que ambas inciden en la investigación sobre los delitos de corrupción.

Finalmente, es posible, a partir del análisis de estos dos casos, sugerir ciertas consideraciones que se deben tomar en cuenta para combatir de manera más efectiva la corrupción en el nivel subnacional. La primera, es reconocer que el contexto y procesos que suceden en las regiones, provincias y distritos responden a distintos factores y dan lugar a diversos escenarios. Por ello, la planificación de una estrategia de lucha contra estos delitos debe ser igual de flexible y adaptable. Por otra parte, es necesario hacer hincapié en la urgente mejora que requieren las entidades fiscalizadoras. Se debe otorgar, tanto a fiscalías como procuradurías, un mayor presupuesto, capacitar mejor a sus funcionarios y asignar a más personal para aliviar la gran carga fiscal de estas oficinas.

Es necesario también identificar las diferencias de complejidad de los delitos que se protegen en redes de corrupción. Para ello, es necesario analizar a los individuos, los enlaces que estos establecen y la forma en que se relacionan. Por último, asegurar la estabilidad laboral y la protección de la integridad física de fiscales y procuradores significaría un gran avance para la mejora en las investigaciones, la captura y sentencia de los acusados, y la posterior recuperación del dinero perdido en estas actividades ilícitas. La solución a los problemas de corrupción a nivel subnacional parece encontrarse en una apuesta por el fortalecimiento de los aparatos fiscalizadores y del Estado. 


\section{Bibliografía}

América TV. (2017). Gerardo Viñas: Poder Judicial amplía por siete meses prisión preventiva.

Recuperado

de http://www.americatv.com.pe/noticias/actualidad/gerardo-vinas-poder-judicialamplia-siete-meses-prision-preventiva-n294804 [Consultado: 20 de noviembre de 2017]

Arévalo, R. (2015). ¿Cuento contigo? La estabilidad en la gestión de César Álvarez (2006-2013). Politai: Revista de Ciencia Política, (11), 111-125.

Coatsworth, J. (1998). "Economic and institutional trajectories in nineteenth century Latin America”. Latin America and the world economy since 1800. Cambridge: Harvard University/David Rockefeller Center for Latin American Studies

Correo (2015a). Fiscalía de la Nación exige al MEF un presupuesto adicional de S./18 millones. Recuperado de https://diariocorreo.pe/politica/fiscalia-de-la-nacion-exigeal-mef-un-presupuesto-adicional-de-s-18-millones-631543/ [Consultado: 22 de marzo de 2017]

Correo (2015b). JNE desaparece a Luchemos por Tumbes. Recuperado de https://diariocorreo.pe/edicion/tumbes/jne-desaparece-a-luchemos-por-tumbes566759/ [Consultado: 15 de enero de 2018]

Degenne, A. \& Forsé, M. (1999). Introducing Social Networks. Londres: Sage Publications 
El Comercio (2016). Tumbes: Gerardo Viñas fue condenado a 11 años de cárcel. Recuperado de https://elcomercio.pe/peru/tumbes/tumbes-gerardo-vinas-condenado11-anos-carcel-146681 [Consultado: 15 de enero de 2017]

Exitosa Noticias (2017). Fiscalía necesita presupuesto de S/3,122 millones para próximo año. Recuperado de https://exitosanoticias.pe/presupuesto-de-fiscalia/ [Consultado: 28 de enero de 2018]

Figueroa, M. (2015). Corrupción y Criminalización del Estado: La experiencia de la descentralización en el Perú. Recuperado de http://perso.unifr.ch/derechopenal/assets/files/articulos/a_20150608_01.pdf [Consultado: 01 de mayo de 2017]

Gibson, E. (2005). Boundary control: Subnational authoritarianism in democratic countries. World Politics. Cambridge, 58, (1), 101-132.

Giraudy, A. (2012). Conceptualizing State Strength: Moving Beyond Strong and Weak States. Revista de Ciencia Política. 32, (3), 599-611.

INGOgob (2017). Base de datos. Recuperado de: http://www.infogob.com.pe/ [Consultado: 18 de abril de 2017]

La República (2016). Fiscal de la Nación insiste en pedir mayor presupuesto. Recuperado de: http://larepublica.pe/politica/825426-fiscal-de-la-nacion-insiste-enpedir-mayor-presupuesto [Consultado: 20 de enero de 2018]

La República (2017a). 14 de 25 gobernadores regionales afrontan investigaciones fiscales. Recuperado de: https://larepublica.pe/politica/1156011-14-de-25gobernadores-regionales-afrontan-investigaciones-fiscales [Consultado: 18 de enero de 2018]

La República (2017b). Sentencian a ex gobernador regional de Tumbes Gerardo Viñas Dioses. Recuperado de: http://larepublica.pe/politica/1159536-sentencian-a-exgobernador-regional-de-tumbes-gerardo-vinas-dioses [Consultado: 15 de enero de 2018]

Lindesmith, A. (1941). Organized crime. The Annals of the American Academy of Political and Social Science. 217, (1), 119-127

Linz, J. y A. Stepan (1996). Problems of democratic transition and consolidation: Southern Europe, South America, and post-communist Europe. Baltimore: Johns Hopkins University Press.

Mann, M. (1986). The Sources of Social Power 1: A History of Power from the Beginning to A.D. 1760. Cambridge: Cambridge University Press

Mény, Y. (1999). La globalización de la Corrupción. Archivos del Presente. 4, (16), 8591.

Ministerio de Justicia y Derechos Humanos. (s/f). Anticorrupción. Recuperado de: Consulta: https://www.minjus.gob.pe/anticorrupcion/ [Consultado: 28 de marzo de 2017] 
Mujica, J. (2005). Relaciones corruptas: poder, autoridad y corrupción en gobiernos locales. Documentos de Debate. (10), 1-41.

O’Donnell, G. (1993). “On the State, Democratization and Some Conceptual Conceptual Problems: A Latin American View with Glances at Some Postcommunist Countries”. World Development. Nueva York, volumen 21, número 8, pp. 1355-1369.

Ojo Público. (2017a). Fondos de papel. Recuperado de: https://fondosdepapel.ojopublico.com/ [Consultado: 18 de abril de 2017]

Ojo Público. (2017b). Investigan a Félix Moreno por soborno de US\$4 millones de Odebrecht. Recuperado de: https://ojo-publico.com/406/odebrecht-fiscalia-acusa-agobernador-regional-del-callao-felix-moreno-por-lavado-de-dinero [Consultado: 26 de mayo de 2017]

Perú 21 (2014). Investigan a Félix Moreno por venta irregular de terreno en el Callao. Recuperado de: https://peru21.pe/politica/investigan-felix-moreno-venta-irregularterreno-callao-177998 [Consultado: 12 abril de 2017]

Perú 21 (2015a). Félix Moreno: Contraloría detectó nuevas irregularidades en el Callao. Recuperado de: https://peru21.pe/politica/felix-moreno-contraloria-detectonuevas-irregularidades-callao-195075 [Consultado: 18 de abril de 2017]

Perú 21 (2015b). Fiscalía pidió 11 años de cárcel para Félix Moreno por construcción inconclusa de sede de Corpac. Recuperado de: $\quad$ https://peru21.pe/politica/fiscalia-pidio-11-anos-carcel-felix-morenoconstruccion-inconclusa-sede-corpac-202658 [Consultado: 18 de abril de 2017]

Perú 21 (2015c). Wilbur Castillo: Félix Moreno negó ser el autor intelectual del asesinato. Recuperado de: https://peru21.pe/lima/wilbur-castillo-felix-moreno-negoautor-intelectual-asesinato-video-205569 [Consultado: 17 de abril de 2017]

Perú 21 (2016). Callao: Obra de avenida Néstor Gambetta habría ocasionado pérdidas de S/55 millones, según Contraloría. Recuperado de: https://peru21.pe/lima/callaoobra-avenida-nestor-gambetta-habria-ocasionado-perdidas-s-55-millones-contraloria231137 [Consultado: 14 de abril de 2017]

Perú 21 (2017a). Félix Moreno: Formalizan investigación contra presidente regional. Recuperado de: https://peru21.pe/politica/felix-moreno-formalizan-investigacionpresidente-regional-66472 [Consultado: 25 de mayo de 2017]

Perú 21 (2017b). Obra Costa Verde, tramo Callao, ya está en manos del fiscal del caso Lava Jato. Recuperado de: https://peru21.pe/politica/obra-costa-verde-tramo-callaomanos-fiscal-caso-lava-jato-69913 [Consultado: 28 de mayo de 2017]

RPP Noticias (2015). Fiscal de la Nación pidió al Congreso un aumento en el presupuesto para su sector. Recuperado de: http://rpp.pe/politica/estado/fiscal-de-lanacion-pidio-al-congreso-un-aumento-en-el-presupuesto-para-su-sector-noticia91734 [Consultado: 20 de enero de 2018] 
RPP Noticias (2016). Gerardo Viñas: ¿quién es y de qué se le acusa al exgobernador de Tumbes? Recuperado de: http://rpp.pe/politica/judiciales/gerardo-vinas-diosesquien-es-y-de-que-se-le-acusa-al-exgobernador-de-tumbes-noticia-973181

[Consultado: 18 de enero de 2018]

Rotberg, R. (2004). When States Fail: Causes and Consequences. Princeton, N.J.: Princeton University Press.

Soifer, H. y M. Vom Hau (2008). "Unpacking the Strength of the State: The Utility of State Infrastructure Power". Studies in Comparative International Development. Washington, volumen 43, número 3-4, pp. 219-30.

Wasserman, S. \& Faust, K. (1994). Social Network Analysis. Cambridge: Cambridge University Press. 